\title{
Spikemoss flora (Selaginella) in Mindanao Island, the Philippines: species composition and phenetic analysis of morphological variations
}

\author{
Majella G. Bautista1, ${ }^{1,}$ Fulgent P. Coritico ${ }^{2}$, Florfe M. Acma ${ }^{2}$ and Victor B. Amoroso ${ }^{2}$
}

\begin{abstract}
The genus Selaginella, commonly referred to as spikemosses, is an important component of the Philippines' lycophytes diversity. Mountain ecosystems in Mindanao island hold diverse species of lycophytes, however the morpho-taxonomy diversity of this group is poorly documented there. The study aimed to determine Selaginella species richness, distribution and phenetic relationships based on morphological characteristics in Mindanao island. Specimens of Selaginella were collected in Mt. Apo, Kidapawan City; Mt. Hamiguitan, Davao Oriental; Mt. Kiamo, Mt. Kitanglad, Mt. Musuan and Mt. Limbawon in Bukidnon; Mt. Timpoong, Camiguin; and Mt. Malindang, Misamis Occidental. The 24 Selaginella species were collected and subjected to numerical phenetic analysis using the PC-ORD program. A total of 11 morphological characters and 44 character states were used in the analyses. Of the 24 species, seven are Philippine endemics, four are potential new species and two species are widely distributed in the areas studied. Results of the phenetic analysis showed four major clusters.
\end{abstract}

KEYWORDS: endemic species, lycopods, Philippines, Selaginellaceae, taxonomy

\section{INTRODUCTION}

The Philippines is known to have a rich plant diversity that includes the lycophyte spikemoss genus Selaginella (Selaginellaceae). Most Selaginella species are small and delicate plants which occur in abundance mainly in tropical zones of the world. Some Selaginella species are used as a source of natural medicines, vegetables, and ornamental plants (Setyawan, 2011). In the Philippines, S. tamariscina (Beuav.) Spring is used to treat wounds, bleeding from peptic ulcers or excessive menstruation, and haemorrhoids (Setyawan, 2009).

In Selaginella taxonomy leaf morphology is primarily used for identification, however, Maideen et al. (2013) and Tan (1974) also recommended using stele anatomy for this purpose. Furthermore, in the Philippines, light microscopy studies were

${ }^{1}$ Natural Science Department, College of Arts and Sciences, University of Southeastern Philippines (USEP), Davao City ${ }^{2}$ Center for Biodiversity Research and Extension in Mindanao (CEBREM), Central Mindanao University (CMU), University Town, Musuan, Bukidnon

*Corresponding author: majellajadegb@gmail.com

Date Submitted: 31 October 2017

Date Accepted: 09 April 2018 conducted by Zamora et al. (1992) and Tan (1974) to study sporangial arrangement patterns and spore ornamentation, respectively, to characterize species.

The Selaginellaceae, in spite of their species abundance, are one of the most understudied lycophyte families with many threatened taxa (Ebihara et al., 2012). Furthermore, inadequate descriptions and fragmented studies on Philippines' Selaginella contributed to the poor taxonomic knowledge of this group (Tan, 1974). Selected mountain ecosystems in Mindanao island, namely, Mt. Apo, North Cotabato; Mt. Hamiguitan, Davao Oriental; Mt. Kiamo and Mt. Limbawon, Bukidnon; Mt. Malindang, Misamis Occidental and Mt. Timpoong, Camiguin hold diverse species of lycophytes which includes species of the family Selaginellaceae. This study aimed to examine morphological characters that contribute to discrimination between species. It is on these aforementioned premises that species composition, distribution and phenetic analysis of Selaginella in Mindanao island were investigated.

\section{MATERIALS AND METHODS}

Entry Protocol. Gratuitous permits (GP) were secured from the Department of Environment and Natural Resources (DENR) in order to conduct surveys and collect specimens in each selected sampling site. Courtesy calls and proper 
entry protocol were also done with concerned local government units (LGU's).

Collection and Processing of Herbarium Specimens and Identification. Specimens of Selaginella were collected in Mt. Apo, Kidapawan City; Mt. Hamiguitan, Davao Oriental; Mt. Kiamo, Mt. Kitanglad, and Mt. Limbawon, Bukidnon; Mt. Timpoong, Camiguin; and Mt. Malindang, Misamis Occidental (Fig. 1). A minimum of four sample replicates of each species were collected and placed in a plastic bag and labelled with standard collecting information (i.e., collector's name, collection number, initial identification, date, and other diagnostic field characters of the plants), and processed and mounted as herbarium specimens at the University Museum of Central Mindanao University for identification and classification. A record of diagnostic characteristics of each collected species was kept in an electronic file. Initial species identification was carried out by the authors using Alston's (1935) monograph. Additionally, final species identification and confirmation were done by the late Dr. Benito C. Tan.

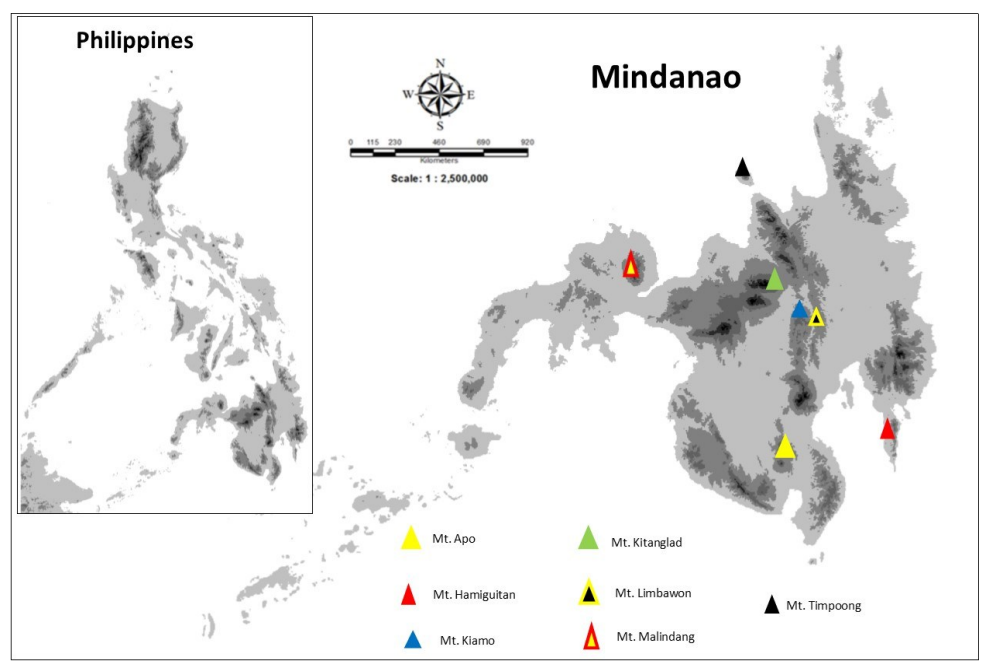

Figure 1. Map of Mindanao island showing the sampling sites for the study.

Numerical Analysis. Qualitative data from morphological characters (Table 1) were tabulated in a matrix and analyzed using R software (Le et al., 2008; Wickham, 2009; Wickham and Francois, 2016; Kassambara and Mundt, 2017; Maechler et al., 2017). Different character states were encoded in a multi-state order. Each coded character state was recorded in binary order for the numerical analysis (Sneath and Sokal, 1973). Cluster analysis was used to estimate form resemblance between species studied. Similarity coefficients were calculated and phenograms constructed using UPGMA (Sokal and Mischener, 1958). Euclidean distance was used to determine group linkage. Principal Component Analysis (PCA) was computed to generate a biplot plot to ascertain similarities and differences among studied species. Megaspores and microspores were measured in the equatorial plane using light microscope under low-power objective.

\section{RESULTS AND DISCUSSION}

Species Composition. The present study documented a total of 24 species of Selaginella from different mountain ecosystems in Mindanao island (Table 2). Of these, 14 were found in Mt. Hamiguitan, 10 in Mt. Apo, while the rest of the mountain ecosystems sampled have lower than ten species each (Table 2). Seven (7) Selaginella species are endemic to the Philippines, four (4) are potentially new species from Mt. Hamiguitan and two (2) are the most widely distributed in the sampled areas of Mindanao island. The seven endemic species are S. agusanensis Hieron., S. gastrophylla Warb., $S$. intertexta Spring, S. jagorii Warb., S. philippina Spring, $S$. magnifica Warb. and S. negrosensis Hieron. (Alston, 1935; Tan, 2013, see Figs. 2 A-G). Selaginella involvens (Sw.) Spring (Fig. 2, I) and S. cupressina (Willd.) Spring (Fig. 2, H) were the most widely distributed of all studied species which are also widespread throughout Asia as reported by Tan (2013).

Phenetic Analyses Based on External Morphology. All Selaginella species collected were subjected to cluster analysis using the $\mathrm{R}$ software. Results of the cluster analysis showed four major clusters (Fig. 3). Cluster I comprised the following species, S. opaca Warb., S. ornata (Hook. \& Grev.) Spring, S. negrosensis, S. intermedia (BI.) Spring, $S$. repanda (Desv.) Spring, $S$. remotifolia, $S$. intertexta, and Selaginella sp. A; Cluster II with the following species: $S$. cupressina, $S$. flagellifera Hieron., $S$. agusanensis, $S$. tamariscina (Beuav.) Spring, and Selaginella sp. C.; Cluster III comprises Selaginella sp. D., S. magnifica, S. gastrophylla, S. engleri Hieron., S. jagorii Warb., Selaginella sp. B., S. Ilanosii Hieron., S. philippina, and $S$. aristata Spring; Cluster IV comprises $S$. alligans Hieron. and $S$. involvens.

Cluster I was composed S. opaca, S. ornata, S. negrosensis, $S$. intermedia, $S$. repanda, $S$. remotifolia, $S$. intertexta, and Selaginella sp. A that shared the following characters: creeping, ascending or caulescent habit, monostele stem anatomy, median leaves short aristate, non-auricled axillary leaves, megaspores yellow to black, globose and with a smooth sculpturing pattern with size ranging from 4 to 5.5 $\mathrm{mm}$ in diameter and microspore size ranging from 1.5 to 4 $\mathrm{mm}$ in diameter.

Cluster II consisted of $\mathcal{S}$. cupressina, $\mathcal{S}$. flagellifera, $\mathcal{S}$. agusanensis, $S$. tamariscina, and Selaginella sp. C with the following shared characters: monostele stem anatomy, nonauricled axillary leaves, tetragonous strobili, megaspores 
Table 1. List of morphological character states for each character used in numerical analysis of Selaginella species in Mindanao island.

\section{Morphological characters}

A. Habit

1 - erect, rooting at base

2 - creeping, ascending or caulescent

3 - climbers, hemi-epiphytic

\section{B. Stele type \\ 1 - monostele \\ 2 - tristele \\ 3 - polystele}

\section{Median Leaves}

1- Short aristate

2- Long aristate

3- non aristate

D. Lateral leaves

1 - ciliated

2 - non-ciliated

3 - denticulate

\section{E. Axillary Leaves}

1 - auricled

2 - non-auricled

3 - non axillary

\section{F. Stomatal Type}

1 - Anomocytic

2 - cyclocytic (encyclocytic)
G. Strobilus

1- Tetragonous

2- Flattened

\section{H. Megaspore}

1 - yellow, globose, smooth

2 - yellow, globose, verrucate

3 - yellow, trilete, verrucate with wing-like flap

4 - yellow, trilete, reticulate with wing-like flap

5 - yellow, trilete, reticulate

6 - yellow, trilete, with rounded, regulate

7 - yellow, trilete, smooth

8 - yellow, globose, monolete, smooth

9 - orange, globose, trilete, reticulate

10 - orange, trilete, baculate

11 - beige, globose, reticulate

12 - blackish, trilelete, reticulate

13 - black, globose, smooth

14 - black, trilete verrucate

15 - black, monolete, verrucate

\section{Microspore}

1 - tetrahedral, trilete, smooth, yellow

2 -tetrahedral, trilete,

yellow

3 - tetrahedral, trilete triangular with straight side and

broadly rounded corners, spinulose, yellow

4 - tetrahedral, triangular with slightly curved sides

and broadly rounded corners, granulose, orange

5 - tetrahedral, trilete,triangular with straight to slightly

concave sides and narrow rounded corners, yellow

6 - tetrahedral, trilete, granulose, yellow yellow to orange to black, trilete, regulate to reticulate sculpturing pattern and size ranging from 2.6 to $6.7 \mathrm{~mm}$ in diameter and microspores are tetrahedral, trilete, with straight to concave sides and broadly rounded corners, yellow and size ranging from 1.3 to $2.8 \mathrm{~mm}$.

Cluster III included Selaginella sp. D, S. magnifica, $S$. gastrophylla, S. engleri, S. jagorii, Selaginella sp. B, $S$. Ilanosii, $S$. philippina, and $S$. aristata, is characterized by erect habit with rhizophores at base, monostele to tristele stem anatomy, long aristate median leaves, non-auricled axillary leaves, anomocytic type of stomata, and megaspores yellow to orange to black, globose to monolete to trilete, size ranging from 2.6 to $9.3 \mathrm{~mm}$ in diameter; microspores tetrahedral, trilete, with broadly rounded corners, granulose to spinulose, yellow with size ranging from 1.6 to $2.8 \mathrm{~mm}$.

Cluster IV consisted of $\mathcal{S}$. alligans and $\mathcal{S}$. involvens which are characterized by climbers, hemi-epiphytic, monostele stem anatomy, long aristate median leaves, non-ciliated lateral leaves, auricled axillary leaves, anomocytic stomata, tetragonous strobili, megaspores yellow, trilete, with winglike flap, verrucate or reticulate, with size ranging from 7 to 9 $\mu \mathrm{m}$ in diameter, microspores tetrahedral, spinulose, yellow with size ranging from 1.5 to $2.9 \mu \mathrm{m}$ in diameter. 


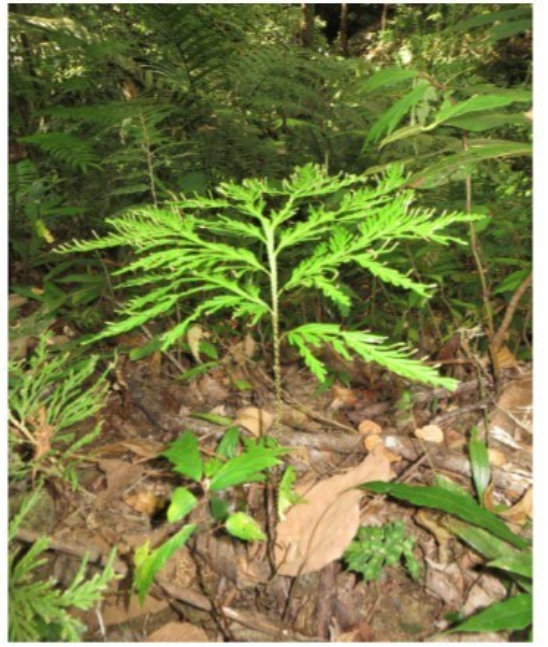

A) S. agusanensis Hieron*

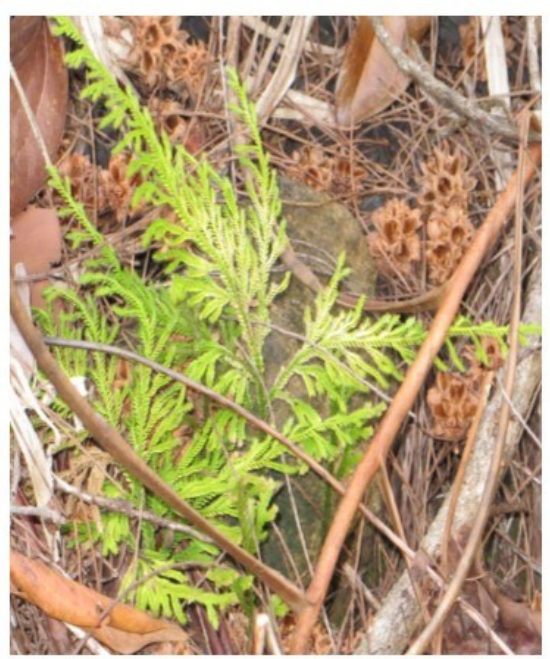

D) S. jagorii Warb.

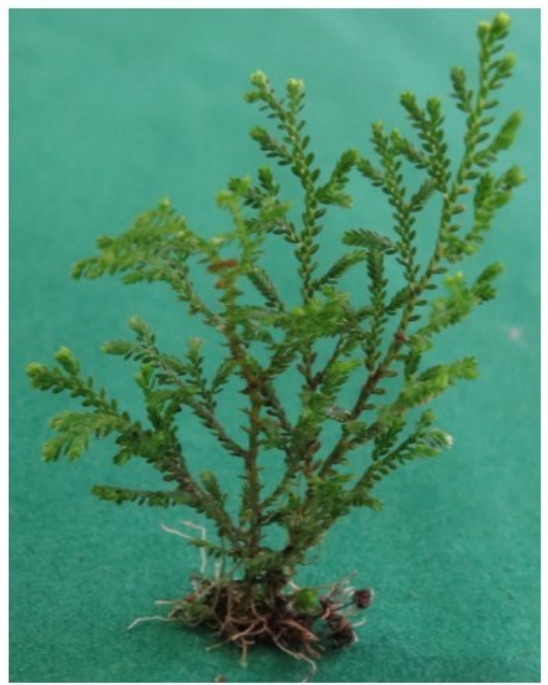

G) S. philippina Spring

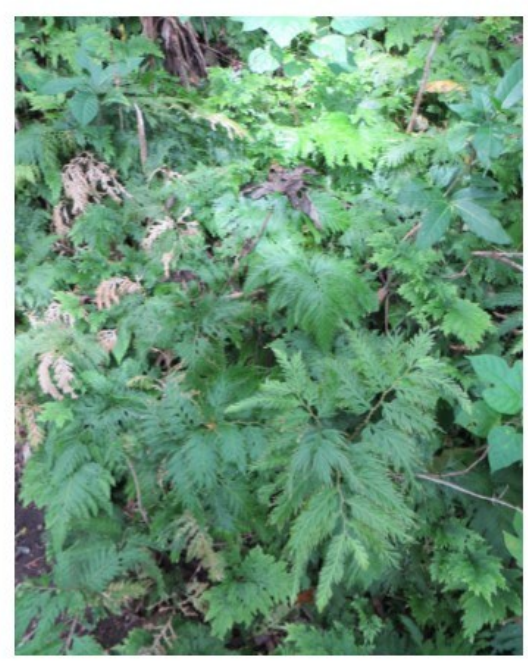

B) S. gastrophylla Warb.*

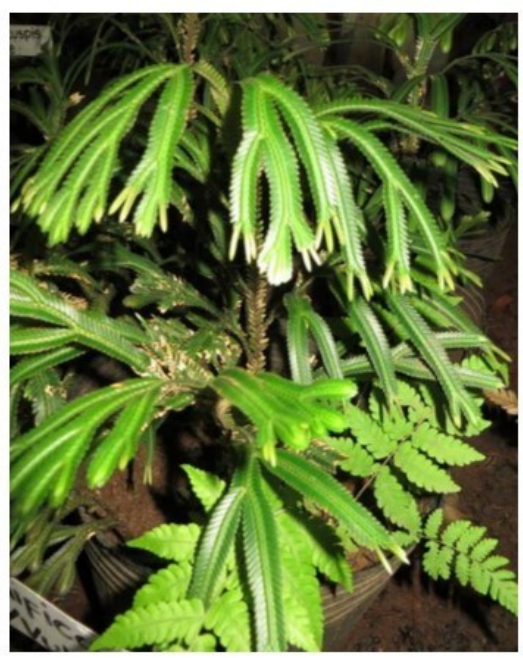

E) S. magnifica Warb.

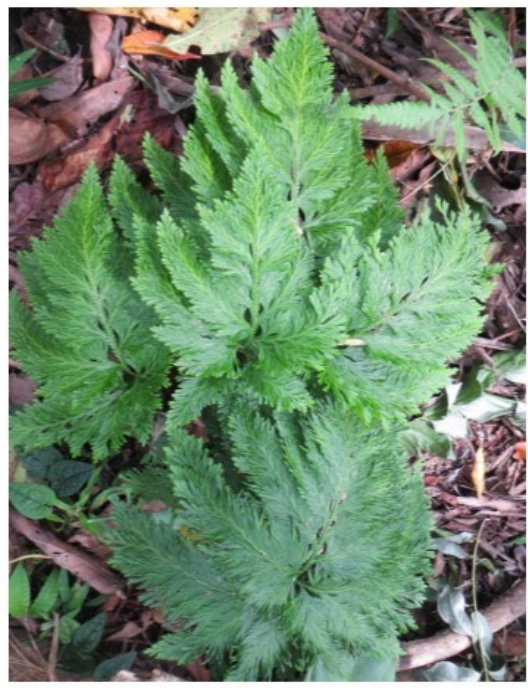

H) S. cupressina (Willd.) Spring

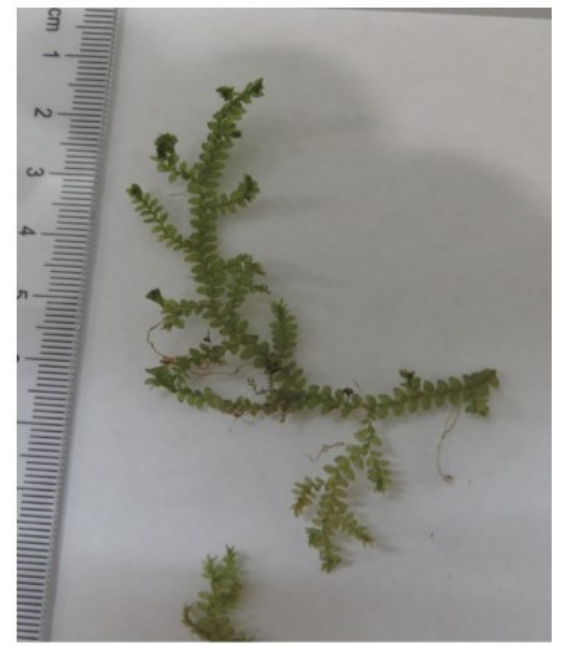

C) S. intertexta Spring.

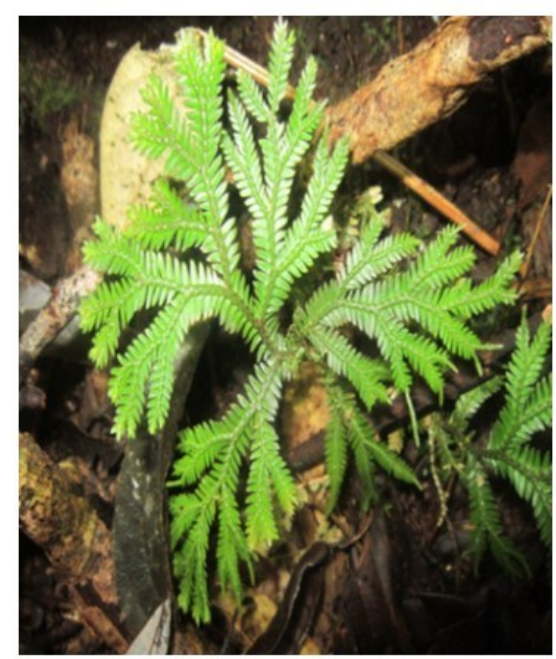

F) S. negrosensis Hieron.

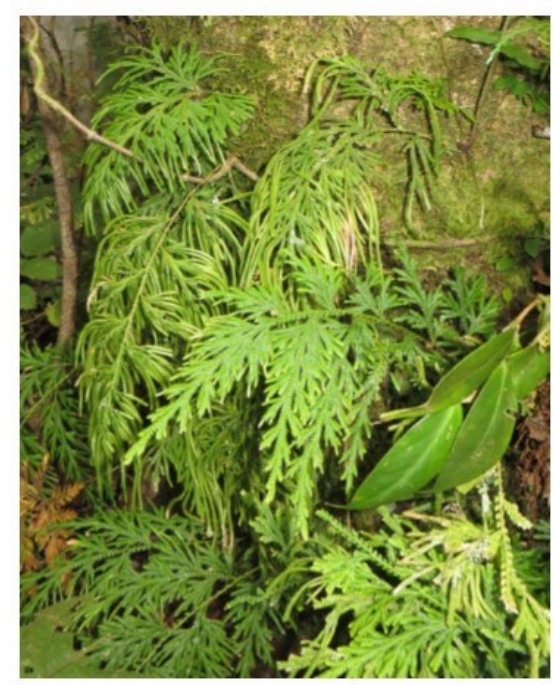

I) S. involvens (Sw.) Spring

Figure 2. Some Philippine endemic and widely distributed Selaginella in Mindanao island. 
Philippine Journal of Systematic Biology | Bautista M. G. et al: Spikemoss flora in Mindanao Island, Philippines

Table 2. Species composition and distribution of Selaginella in Mindanao Island

\section{Distribution}

\begin{tabular}{|c|c|c|c|c|c|c|c|c|}
\hline & & & & & & & \\
\hline & Species & $\begin{array}{l}\text { Mt. } \\
\text { Apo }\end{array}$ & $\begin{array}{l}\text { Mt. } \\
\text { Hamiguitan }\end{array}$ & Mt. Kiamo & $\begin{array}{l}\text { Mt. } \\
\text { Kitanglad }\end{array}$ & Mt.Limbawon & Mt. Malindang & Mt. Timpoong \\
\hline 1. & Selaginella agusanensis Hieron & & $\sqrt{ }$ & & & & & \\
\hline 2. & Selaginella alligans Hieron & & $\sqrt{ }$ & & & & & \\
\hline 3. & Selaginella aristata Spring. & $\sqrt{ }$ & & & & & & \\
\hline 4. & $\begin{array}{l}\text { Selaginella cupressina (Willd.) } \\
\text { Spring }\end{array}$ & $\sqrt{ }$ & $\sqrt{ }$ & $\sqrt{ }$ & $\sqrt{ }$ & $\sqrt{ }$ & $\sqrt{ }$ & $\sqrt{ }$ \\
\hline 5. & Selaginella engleri Hieron & $\sqrt{ }$ & $\sqrt{ }$ & & & & & \\
\hline 6. & Selaginella flagellifera Hieron. & $\sqrt{ }$ & & & & $\sqrt{ }$ & & \\
\hline 7. & Selaginella gastrophylla Warb. & $\sqrt{ }$ & $\sqrt{ }$ & & & $\sqrt{ }$ & & $\sqrt{ }$ \\
\hline 8. & Selaginella intermedia (BI.) Spring & $\sqrt{ }$ & & $\sqrt{ }$ & & $\sqrt{ }$ & & \\
\hline 9. & Selaginella intertexta Spring & & $\sqrt{ }$ & & & & & \\
\hline 10. & Selaginella involvens (Sw.) Spring & $\sqrt{ }$ & & $\sqrt{ }$ & $\sqrt{ }$ & $\sqrt{ }$ & $\sqrt{ }$ & $\sqrt{ }$ \\
\hline 11. & Selaginella jagorii Warb. & & $\sqrt{ }$ & & & & & \\
\hline 12. & Selaginella Ilanosii Hieron. & & $\sqrt{ }$ & & & & & \\
\hline 13. & Selaginella magnifica Warb. & $\sqrt{ }$ & & $\sqrt{ }$ & $\sqrt{ }$ & & & \\
\hline 14. & Selaginella negrosensis Hieron. & $\sqrt{ }$ & $\sqrt{ }$ & & & & & \\
\hline 15. & Selaginella opaca Warb. & & & $\sqrt{ }$ & & & & \\
\hline 16. & $\begin{array}{l}\text { Selaginella ornata (Hook. \& Grev.) } \\
\text { Spring }\end{array}$ & & & & & $\sqrt{ }$ & & \\
\hline 17. & Selaginella philippina Spring & & & & & & $\sqrt{ }$ & \\
\hline 18. & Selaginella remotifolia Spring & $\sqrt{ }$ & & & & & & \\
\hline 19. & Selaginella repanda (Desv.) Spring & & & & & $\sqrt{ }$ & & \\
\hline 20. & $\begin{array}{l}\text { Selaginella tamariscina (Beuav.) } \\
\text { Spring }\end{array}$ & & $\sqrt{ }$ & & & & & \\
\hline 21. & Selaginella sp. A & & $\sqrt{ }$ & & & & & \\
\hline 22. & Selaginella sp. B & & $\sqrt{ }$ & & & & & \\
\hline 23. & Selaginella sp. C & & $\sqrt{ }$ & & & & & \\
\hline 24. & Selaginella sp. D & & $\sqrt{ }$ & & & & & \\
\hline
\end{tabular}




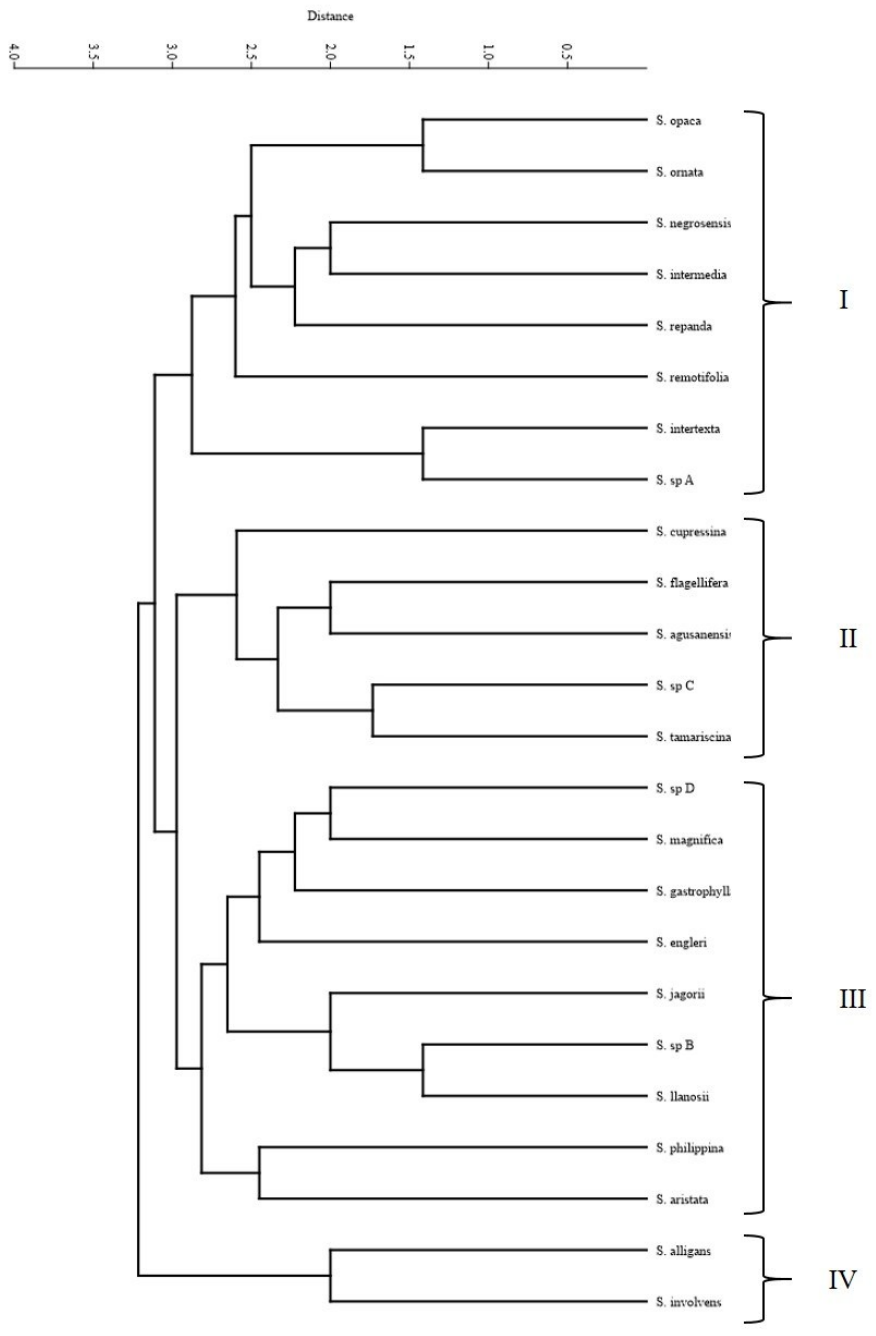

Figure 3. Phenogram of Selaginella in Mindanao island based on morphology.

Findings of the present study on some of the morphological characters of some Selaginella in Mindanao island were similar to reports done by other authors on Selaginella species that are widespread in Asia like $\mathcal{S}$. flagellifera, $\mathcal{S}$. involvens, $S$. intermedia, $S$. remotifolia, $S$. repanda, and $S$. tamariscina. Dahlen (1988) and Maideen et al. (2013) reported monostele, tristele and polystele stem anatomical variations in Hongkong and Malaysian species of Selaginella which were also observed in species from Mindanao island. On the other hand stomatal types of Selaginella in the present study varied as compared to the Hongkong Selaginella species that exhibited only one type of stomata which is actinocytic (Dahlen, 1988). In terms of Selaginella megaspores, several authors reported color ranges from white and yellow to brown and black; tetrahedral, globose, trilete with smooth to reticulate rugulate to verrucate sculpturing pattern; microspores are yellow to brown, hemispherical, tetrahedral, trilete, granulose to spinulose (Korall and Taylor, 2006; Singh, et al., 2014; Singh, et al., 2016; Zhou, et al., 2015).
Table 3 shows the first 15 principal components explaining $93.51 \%$ of total morphometric variation. The first axis (PC1) with an eigenvalue of 5.674 explained $15.34 \%$ of the total variance. As shown in Table 4, five morphological characters with the highest loadings on PC1 are creeping habit (A2), short aristate median leaves (C1), long aristate median leaves $(\mathrm{C} 2)$, tetragonous strobilus and megaspores $(\mathrm{H} 1)$ that are yellow, globose and smooth. These mean that habit, median leaves, strobili and megaspores are morphological characters that are responsible for the clustering of Selaginella species studied. The second principal component accounted for $12.11 \%$ of the total variation which correlated with erect habit (A1), climbers, hemi-epiphytic habit (A3), auricled and non-auricled axillary leaves (E1, E2) and megaspores that are yellow, trilete, verrucate wing-like flap $(\mathrm{H} 3)$. Similarly, in his study on the Cyatheaceae, Coritico (2014) reported a high morphological variation of 94.57\% from analyzing 62 morphological characters and 182 character states. In contrast, Lasalita-Zapico et al. (2011) conducted a study on the phenotypic variation of pteridophytes belonging to different families in which total variation was quite low. As the number of assessed morphological characters increases, similarity between species also increases; even with large numbers of characters there are always some differences (Sneath, 1995). This means that the higher the number of morphological characters to be examined in a family the higher the cumulative percentage of variation that will reveal phenotypic relationships among species.

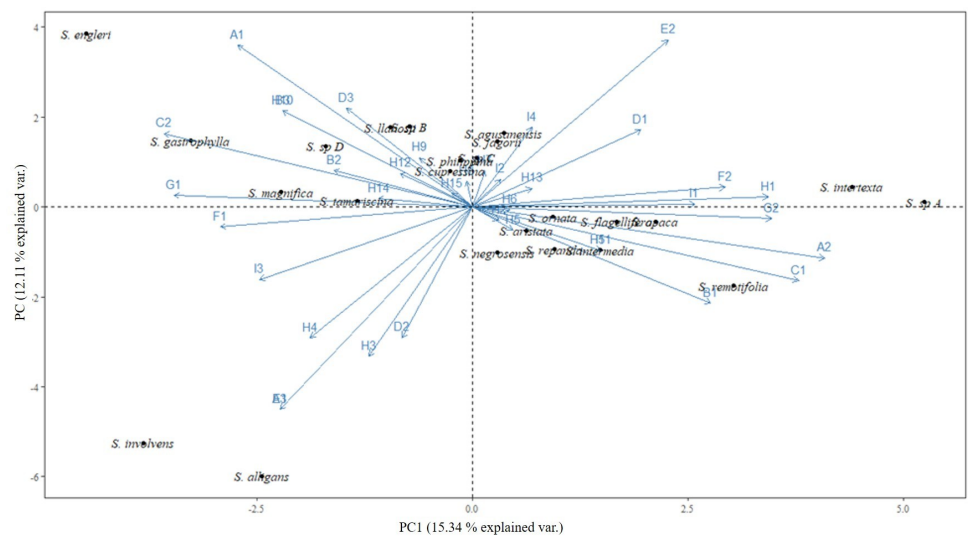

Figure 4. PCA biplot of Selaginella species in Mindanao island showing qualitative characters.

The PCA biplot (Fig. 4) shows the variability of Selaginella species and qualitative characters in Mindanao samples along PC 1 and 2. Species that are close together corresponded to morphological characters that have similar scores on the components displayed in the biplot (Fig. 4). The points also corresponded to morphological variations that have similar values on the vectors. Apparently, having similar habit of climber, hemi-epiphytic (A3), non-ciliated 
Table 4. Morphological characters and component matrix of Selaginella species in Mindanao island.

\begin{tabular}{|c|c|c|c|c|c|c|c|c|c|c|c|c|c|c|c|}
\hline \multirow{2}{*}{$\begin{array}{c}\text { Morphological } \\
\text { characters }\end{array}$} & \multicolumn{15}{|c|}{ Component } \\
\hline & PC 1 & PC 2 & PC 3 & PC 4 & PC 5 & PC 6 & PC 7 & PC 8 & PC 9 & PC10 & PC11 & PC12 & PC13 & PC14 & PC15 \\
\hline $\mathrm{A} 1$ & -0.208 & 0.309 & -0.034 & 0.129 & 0.118 & -0.153 & 0.137 & -0.110 & -0.122 & -0.190 & -0.076 & -0.065 & -0.003 & 0.014 & 1.938 \\
\hline A2 & 0.311 & -0.097 & 0.047 & -0.150 & -0.012 & 0.197 & -0.206 & 0.102 & 0.113 & 0.191 & 0.094 & 0.053 & 0.014 & -0.002 & -1.354 \\
\hline A3 & -0.170 & -0.386 & -0.022 & 0.031 & -0.192 & -0.070 & 0.114 & 0.019 & 0.023 & 0.007 & -0.028 & 0.024 & -0.019 & -0.021 & 1.706 \\
\hline B1 & 0.211 & -0.183 & -0.044 & 0.323 & 0.096 & -0.015 & 0.017 & 0.199 & -0.159 & -0.248 & 0.122 & -0.035 & 0.094 & 0.090 & 4.984 \\
\hline B2 & -0.123 & 0.070 & 0.039 & -0.094 & 0.107 & -0.064 & -0.115 & -0.462 & 0.325 & 0.310 & -0.204 & 0.062 & -0.110 & -0.108 & -8.125 \\
\hline B3 & -0.168 & 0.183 & 0.021 & -0.352 & -0.240 & 0.084 & 0.091 & 0.186 & -0.105 & 0.033 & 0.036 & -0.013 & -0.020 & -0.016 & 4.120 \\
\hline $\mathrm{C} 1$ & 0.288 & -0.140 & 0.094 & -0.060 & -0.026 & 0.283 & 0.056 & -0.088 & -0.209 & 0.037 & -0.180 & -0.022 & -0.029 & -0.020 & 2.391 \\
\hline $\mathrm{C} 2$ & -0.273 & 0.140 & -0.135 & 0.018 & 0.005 & -0.298 & -0.150 & 0.143 & 0.192 & 0.005 & 0.115 & 0.022 & -0.021 & -0.024 & 3.024 \\
\hline D1 & 0.149 & 0.147 & -0.241 & 0.260 & -0.245 & 0.174 & -0.028 & -0.046 & 0.153 & -0.090 & -0.012 & 0.026 & -0.043 & -0.061 & 3.578 \\
\hline D2 & -0.062 & -0.249 & 0.096 & -0.161 & 0.326 & -0.214 & -0.180 & 0.037 & -0.102 & 0.183 & -0.067 & -0.047 & -0.062 & -0.030 & 4.627 \\
\hline D3 & -0.112 & 0.189 & 0.178 & -0.240 & -0.199 & 0.064 & 0.212 & 0.106 & -0.121 & -0.098 & 0.024 & 0.039 & 0.098 & 0.085 & -4.054 \\
\hline E1 & -0.170 & -0.386 & -0.022 & 0.031 & -0.192 & -0.070 & 0.114 & 0.019 & 0.023 & 0.007 & -0.028 & 0.024 & -0.019 & -0.021 & 7.238 \\
\hline E2 & 0.173 & 0.319 & -0.040 & -0.089 & 0.129 & 0.043 & -0.231 & 0.062 & -0.050 & 0.057 & -0.076 & -0.021 & -0.059 & -0.047 & 4.787 \\
\hline F1 & -0.223 & -0.038 & -0.327 & -0.004 & 0.169 & 0.253 & 0.086 & -0.076 & -0.027 & 0.073 & 0.123 & -0.077 & -0.011 & -0.002 & 1.627 \\
\hline F2 & 0.223 & 0.038 & 0.327 & 0.004 & -0.169 & -0.253 & -0.086 & 0.076 & 0.027 & -0.073 & -0.123 & 0.077 & 0.011 & 0.002 & -2.090 \\
\hline $\mathrm{G} 1$ & -0.264 & 0.022 & 0.246 & 0.213 & -0.013 & 0.210 & -0.106 & 0.148 & 0.102 & 0.041 & -0.098 & -0.079 & -0.017 & 0.012 & -3.619 \\
\hline G2 & 0.264 & -0.022 & -0.246 & -0.213 & 0.013 & -0.210 & 0.106 & -0.148 & -0.102 & -0.041 & 0.098 & 0.079 & 0.017 & -0.012 & -3.212 \\
\hline $\mathrm{H} 1$ & 0.262 & 0.019 & -0.033 & -0.035 & -0.326 & -0.206 & 0.007 & -0.110 & 0.121 & 0.091 & 0.044 & -0.242 & -0.031 & 0.026 & 1.037 \\
\hline $\mathrm{H} 2$ & 0.023 & -0.025 & -0.091 & -0.112 & 0.117 & -0.056 & -0.035 & -0.308 & -0.500 & -0.209 & -0.040 & -0.042 & 0.154 & -0.166 & -2.887 \\
\hline $\mathrm{H} 3$ & -0.092 & -0.284 & 0.004 & 0.013 & -0.137 & 0.043 & 0.123 & -0.057 & -0.131 & 0.021 & -0.226 & -0.040 & -0.063 & 0.055 & 5.774 \\
\hline $\mathrm{H} 4$ & -0.144 & -0.250 & -0.034 & 0.029 & -0.129 & -0.139 & 0.035 & 0.082 & 0.163 & -0.012 & 0.188 & 0.073 & 0.037 & -0.085 & -5.774 \\
\hline $\mathrm{H} 5$ & 0.036 & -0.045 & 0.107 & 0.007 & 0.143 & 0.179 & -0.006 & 0.117 & -0.121 & 0.348 & 0.431 & -0.236 & -0.319 & -0.265 & -3.299 \\
\hline $\mathrm{H} 6$ & 0.033 & -0.006 & 0.232 & 0.011 & 0.051 & -0.201 & -0.301 & 0.276 & -0.055 & -0.117 & -0.248 & 0.264 & -0.115 & -0.159 & -2.170 \\
\hline $\mathrm{H} 7$ & 0.011 & 0.069 & -0.091 & 0.179 & -0.021 & 0.110 & 0.188 & 0.078 & -0.113 & 0.079 & -0.471 & -0.160 & -0.413 & -0.114 & -2.887 \\
\hline $\mathrm{H} 8$ & -0.006 & 0.049 & -0.166 & 0.005 & 0.135 & -0.340 & 0.139 & 0.065 & -0.175 & 0.231 & 0.181 & 0.222 & -0.023 & -0.030 & 2.887 \\
\hline $\mathrm{H} 9$ & -0.047 & 0.094 & 0.314 & 0.082 & 0.105 & 0.045 & 0.240 & -0.391 & 0.178 & -0.006 & 0.022 & 0.094 & 0.147 & 0.114 & 3.373 \\
\hline $\mathrm{H} 10$ & -0.168 & 0.183 & 0.021 & -0.352 & -0.240 & 0.084 & 0.091 & 0.186 & -0.105 & 0.033 & 0.036 & -0.013 & -0.020 & -0.016 & 1.996 \\
\hline $\mathrm{H} 11$ & 0.114 & -0.083 & -0.104 & -0.269 & 0.280 & 0.055 & 0.222 & 0.177 & 0.319 & -0.196 & -0.127 & -0.027 & -0.005 & 0.006 & -7.774 \\
\hline $\mathrm{H} 12$ & -0.064 & 0.064 & -0.093 & 0.094 & -0.024 & 0.031 & -0.162 & -0.016 & 0.149 & -0.427 & 0.138 & -0.198 & -0.036 & -0.531 & 2.887 \\
\hline $\mathrm{H} 13$ & 0.052 & 0.036 & -0.191 & 0.083 & -0.086 & 0.276 & -0.158 & -0.029 & 0.047 & -0.033 & 0.162 & 0.560 & -0.108 & 0.250 & -5.804 \\
\hline $\mathrm{H} 14$ & -0.083 & 0.016 & -0.037 & 0.005 & 0.118 & -0.089 & -0.225 & 0.033 & -0.038 & -0.144 & 0.062 & -0.383 & -0.247 & 0.675 & -1.013 \\
\hline H15 & -0.018 & 0.026 & -0.084 & 0.093 & 0.048 & 0.098 & -0.138 & 0.184 & 0.016 & 0.274 & -0.146 & -0.249 & 0.736 & 0.005 & 8.818 \\
\hline 11 & 0.197 & 0.005 & -0.005 & -0.053 & -0.273 & -0.160 & -0.023 & -0.148 & 0.135 & 0.020 & 0.106 & -0.327 & -0.041 & 0.034 & -4.246 \\
\hline 12 & 0.025 & 0.053 & 0.407 & 0.150 & 0.146 & 0.049 & 0.217 & -0.001 & -0.043 & -0.049 & 0.272 & 0.028 & 0.003 & -0.016 & 3.633 \\
\hline 13 & -0.189 & -0.138 & -0.097 & -0.196 & -0.095 & 0.133 & -0.412 & -0.164 & -0.105 & -0.115 & -0.081 & 0.046 & 0.018 & -0.004 & 5.049 \\
\hline 14 & 0.052 & 0.152 & -0.262 & 0.239 & -0.043 & -0.164 & 0.177 & 0.188 & -0.049 & 0.280 & -0.180 & 0.087 & -0.003 & 0.003 & -5.607 \\
\hline 15 & 0.114 & -0.083 & -0.104 & -0.269 & 0.280 & 0.055 & 0.222 & 0.177 & 0.319 & -0.196 & -0.127 & -0.027 & -0.005 & 0.006 & -7.774 \\
\hline
\end{tabular}


Table 3. Variance extracted from first 15 axes using morphological characters of Selaginella in Mindanao Island

\begin{tabular}{cccc}
\hline PC & Eigenvalue & \% variance & $\begin{array}{c}\text { Cum. \% } \\
\text { Variance }\end{array}$ \\
\hline 1 & 5.674 & 15.34 & 15.34 \\
2 & 4.482 & 12.11 & 27.45 \\
3 & 3.612 & 9.76 & 37.21 \\
4 & 3.069 & 8.29 & 45.51 \\
5 & 2.746 & 7.42 & 52.93 \\
6 & 2.408 & 6.51 & 59.44 \\
7 & 2.049 & 5.54 & 64.97 \\
8 & 1.752 & 4.74 & 69.71 \\
9 & 1.625 & 4.39 & 74.10 \\
10 & 1.449 & 3.92 & 78.02 \\
11 & 1.346 & 3.64 & 81.66 \\
12 & 1.211 & 3.27 & 84.93 \\
13 & 1.077 & 2.91 & 87.84 \\
14 & 1.055 & 2.85 & 90.69 \\
15 & 1.043 & 2.82 & 93.51 \\
\hline
\end{tabular}

lateral leaves (D2) and megaspores that are yellow, trilete with wing-like flap $(\mathrm{H} 3 \& \mathrm{H} 4)$ clustered $S$. alligans and $S$. involvens in the lower left corner of the plot. On the other hand, the divergence of $S$. engleri from the rest of the species to the upper corner of the plot was characterized by erect in habit (A1), large tripinnate plant with polystele stem anatomy (B3) and megaspores that are orange, trilete, baculate and with a size ranging from 7 to $9 \mu \mathrm{m}$ in diameter $(\mathrm{H} 10)$. On the other hand, $\mathcal{S}$. tamariscina which was characterized by radially symmetrical leaf arrangement as compared to the rest of the species studied which have distinct lateral, median and axillary leaves (Bold et al., 1980) was not seen in the plot as having diverged from the rest of the species because the radially symmetrical leaf arrangement was not included among the morphological character states that were analyzed. In their study on Philippine Selaginella, Tan (1974) and Zamora et al. (1992) reported that spore morphology and strobilar organization were responsible for the groupings of Selaginella species they have studied. Similarly, several authors reported the importance of megaspore morphology in the discrimination of Selaginella species (Korall and Taylor, 2006; Singh et al., 2014; Singh et al., 2016; Zhou et al., 2015). Selaginella species that are closer together in the biplot have higher correlation. The clustering of majority of Selaginella species in a biplot is indicative of morphological similarities.

\section{CONCLUSION AND RECOMMENDATION}

Based on the results of the study, morphological traits such as habit, median leaves, axillary leaves and megaspores provided distinct discrimination for the clustering of Selaginella species in Mindanao island. Although light microscopy revealed some details of the spores examined, it is recommended that SEM examination be done for more detailed description of spores of the species studied as it has significance to the taxonomy of Selaginella.

\section{ACKNOWLEDGEMENTS}

The authors would like to thank the following: the late Dr. Benito C. Tan, for confirming the identification of all the specimens collected; Dr. Samuel Herbert Mamora of University of Southeastern Philippines for the statistical analysis; the Department of Environment and Natural Resources (DENR) for the gratuitous permits (GP); Laboratory and Facilities Unit of Center for Biodiversity Research and Extension in Mindanao (CEBREM) of Central Mindanao University and the Commission on Higher Education (CHED) for funding the study.

\section{LITERATURE CITED}

Alston, A.H.G. 1935. The Philippine species of Selaginella. Philippine Journal of Science, 58: 359-383.

Amoroso, V.B. and R. Aspiras.2011. Hamiguitan Range: A sanctuary for native flora. Saudi Journal of Biological Sciences, 18: 7-15.

Amoroso, V.B., L.D. Obsioma, J.B. Arlalejo, R.A. Aspiras, D.P. Capili, J.J.A. Polizon and E.B. Sumile. 2009. Inventory and conservation of endangered, endemic and economically important flora of Hamiguitan Range, southern Philippines. Blumea, 54: 71-76.

Bold, H.C., C. J. Alexopoulos and T. Delevoryas. 1980. Morphology of plants and fungi. 4th edition. New York, Harper and Row Publishers.

Coritico, F.P. 2014. Morpho-taxonomy and distribution of family Cyatheaceae in Mindanao. Central Mindanao University. Unpublished master's thesis. 87p.

Dahlen, M.A. 1988. Taxonomy of Selaginella: A study of characters, techniques, and classification in the Hong Kong species. Botanical Journal of the Linnaean Society, 98: 277-302.

Ebihara, A., C.R.F. Jenkins, B.S. Paris, X.C. Zhang, Y.H. Yang, W.L. Chiou, H. M, Chang, S. Lindsay, D. Middleton, M. Kato, T.N. Praptosuwiryo, V.B. Amoroso, J.F. Barcelona, R.H.G. Ranil, C.H. Park, N. Murakami and A. Hoya. 2012. Rare and threatened pteridophytes of Asia. An enumeration of narrowly distributed taxa. 
Bulletin of the National Museum of Nature and Science, Series B (Botany) 38: 93-119.

Hu, X.Y., J.W. Zhai, F.G. Wang and X.L. Xu. 2010. Simple treatment to investigate spore ornamentation of ferns for SEM observation from herbarium specimens. Pakistan Journal of Botany, 42: 2335-2338.

Kassambara, A. and F. Mundt. 2017. factoextra: extract and visualize the results of multivariate data analyses. $R$ package version 1.0.4.999. http://www.sthda.com/english/ rpkgs/ factoextra.

Korall, P. and W.A. Taylor. 2006. Megaspore morphology in the Selaginellaceae in a phylogenetic context: A study of the megaspore surface and wall structure using scanning electron microscopy. Grana, 45: 22-60.

Lasalita-Zapico, F., C.H. Aguilar, B. Lon and N. Bagay. 2011. Phenotypic variations of extant ferns in Mt. Hamiguitan range, Mindanao Island, Philippines. World Applied Sciences Journal, 12: 979-987.

Le, S., J. Josse and F. Husson. 2008. FactoMineR: An R package for multivariate analysis. Journal of Statistical Software, 25: 1-18.

Maechler, M., P. Rousseeuw, A. Struyf, M. Hubert and K. Hornik. 2017. Cluster: Cluster Analysis Basics and Extensions. R package version 2.0.6.

Maideen, H., A.N. Hazwani, Z. Nurfarahain, A. Damanhuri, T. Noraini, G. Rusea, L. Qistina and M. Mas Noryante. 2013. Systematic significance of stipe anatomy of Selaginella (Selaginellaceae) in Peninsular Malaysia. Sains Malaysiana, 42: 693-696.

Mendoza, R.C. and C.V. Zamora. 1981. Studies on the Selaginella species in the Philippines, II. Leaf epidermal elements. Natural and Applied Science Bulletin, 33: 175220.

Setyawan, A.D. 2009. Traditional utilization of Selaginella: Field research and literature review. Nusantara BioScience Journal of Biological Science, 1: 146-154.

Setyawan, A.D. 2011. Review: Natural products from genus Selaginella (Selaginellaceae). Nusantara BioScience Journal of Biological Science, 3: 44-58.

Singh, S.K., N.K. Dubey and G. K. Srivastava. 2016. The microspore morphology of some species of Selaginella (Selaginellaceae) from India. Palynology, 40: 216-229.

Singh, S.K., B.B. Yada, M. Srivastava, P.K. Shukla and G.K. Srivastava. 2014. Comparative morphological studies on spikes of Indian Selaginella Beauv. Plant Systematics and Evolution, 300: 1235-1245.

Sneath, P.H.A.1995. Thirty years of numerical taxonomy. Systematic Biology, 44: 281-298.

Sneath, P. H. A. and R. R. Sokal. 1973. Numerical taxonomy. San Francisco, W. H. Freeman.

Sokal R. and C. Michener. 1958. A statistical method for evaluating systematic relationships. University of Kansas Science Bulletin, 38: 1409-1438.
Tan, B.C. 1974. Sporangial distribution and sporal morphology of the Philippine Selaginella. University of the Philippines. Unpublished master's Thesis. 97p.

Tan, B.C. 2013. The Selaginella flora, a good indicator of the Philippine Pleistocene island groups. Philippine Journal of Science, 142: 211-213.

Wickham. H. 2009. ggplot2: elegant graphics for data analysis. New York, Springer-Verlag.

Wickham, H. and R. Francois. 2016. dplyr: A grammar of data manipulation. $\mathrm{R}$ package version 0.5.0. https:// CRAN.R-project.org/package $=$ dply

Zamora, P.M., B.C. Tan, V.B. Bagaoisan-Cosico, R.A. Balagat and M.R.F. Mercado. 1992. Strobilar organization in Philippine species of Selaginella. Science Diliman, 4: 5-26.

Zhou, X.M., C.J. Rothfels, L. Zhang, Z.R. He, T.L. Pechon, H. He, N.T. Lu, R. Knapp, D. Lorence, X.J. He, X.F. Gao, and L.B. Zhang. 2015. A large-scale phylogeny of the lycophyte genus Selaginella (Selaginellaceae: Lycopodiopsida) based on plastid and nuclear loci. Cladistics, 32: 360-389. 